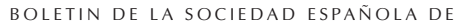

\section{Desarrollo de color y aparición de tonalidades en piezas de pavimento extruido esmaltado, tipo rústico}

\author{
F. FERRANDO $(*)$, J.C.ORTA $(*)$, A. MORENO(**), V. SANZ $(* *)$, M.J. ORTS $(* *)$, R. DE LEMUS(**) \\ $(*)$ Cañada, S.A. Gres de Aragón \\ (**)Instituto de Tecnología Cerámica. Asociación de Investigación de las Industrias Cerámicas. Universitat Jaume I. Castellón. España
}

Ante un problema de tonos en piezas esmaltadas de producción industrial, se ha abordado el estudio de las variables que afectan a la aparición de tonalidades, así como el mecanismo por el que el esmalte desarrolla el color.

Palabras clave: pavimento, tonalidades, variables de proceso

Colour development and shades in glazed, rustic, extruded floor tile.

A study was undertaken of certain process variables affecting the appearance of shades in glazed floor tile manufacture, and of the colour-developing mechanism involved in the glaze, as a result of a problem of shades in industrial glazed tile production.

Key words: floor tile, shades, process variables

\section{INTRODUCCIÓN Y OBJETIVOS}

Uno de los requisitos básicos de las baldosas de pavimento rústico esmaltado es la homogeneidad de color, dentro de la destonificación habitual de este tipo de producto. Sin embargo, esta exigencia es muchas veces difícil de conseguir, ya que los esmaltes empleados suelen tener una elevada sensibilidad a las variables del proceso productivo, presentando frecuentemente problemas por aparición de tonos (1) (2).

Los tonos se pueden definir como alteraciones de la apariencia superficial, en piezas de un mismo modelo, que son detectadas visualmente por un observador. La percepción del color de un objeto está relacionada con la interacción de la luz con el mismo. Si tanto la fuente de iluminación como el observador se mantienen constantes, los tonos serán debidos únicamente a modificaciones de las características del producto.

En este trabajo se han determinado las variables que, mayoritariamente, afectan a la aparición de tonos en piezas de pavimento rústico esmaltado, en las que como esmalte se emplea una mezcla de materias primas de naturaleza exclusivamente cristalina : arcillas blancas, óxidos no cromóforos, silicatos y carbonatos. Con estos materiales, en la proporción adecuada, se prepara una suspensión que se aplica sobre el soporte crudo, previamente recubierto de una capa de engobe. Posteriormente, el conjunto se somete a un tratamiento térmico a alta temperatura $\left(1285^{\circ} \mathrm{C}\right.$ de temperatura máxima) produciéndose fusiones, descomposiciones y otras reacciones, que dan como resultado un vidriado de color marrón-anaranjado.

El esmalte ensayado no contiene pigmentos ni elementos cromóforos, a excepción del pequeño porcentaje de hierro que puedan tener las arcillas (3) (4). Por este motivo se ha planteado un estudio con objeto de determinar el mecanismo por el que se desarrolla el color en este esmalte y la influencia de algunas variables (de aplicación y cocción) sobre el desarrollo del color. El intervalo de las variables analizadas se ha mantenido dentro de los limites de variación de las mismas a nivel industrial.

\section{MATERIALES Y PROCEDIMIENTO EXPERIMENTAL.}

Se ha utilizado el soporte, engobe y esmalte de producción industrial con los que se fabrican piezas de pavimento extruido vidriado tipo rústico. Los soportes se han esmaltado en el laboratorio y también se han utilizado piezas crudas esmaltadas a nivel industrial.

Las piezas, una vez secas, se han cocido en horno eléctrico de laboratorio con el ciclo térmico que se representa en la figura 1 . Con este ciclo se han realizado cocciones modificando la temperatura máxima, el tiempo de permanencia a dicha temperatura, el enfriamiento y la atmósfera del horno (\% de $\left.\mathrm{O}_{2}\right)$.

Las fases cristalinas presentes en la mezcla cruda y en el vidriado resultante se han determinado por difracción de rayos $\mathrm{X}$ (DRX). El aspecto y microestructura de las superficies vidriadas se ha observado con un microscopio óptico y un microscopio electrónico de barrido que lleva incorporado un equipo de microanálisis por dispersión de energías de rayos $\mathrm{X}$ (EDX).

El color de las superficies vidriadas se determinó con un espectrofotómetro de reflectancia difusa. Las coordenadas medidas fueron las CIE L*a* ${ }^{*}$, así como $\Delta \mathrm{E}$, cuyo significado físico es la diferencia de color, respecto a una referencia. La 
pieza seleccionada como referencia fue una de las que se utilizan como tal para la clasificación de las piezas, a nivel industrial.

Con el fin de distinguir si las piezas medidas eran más claras o más oscuras que la pieza de referencia, se ha añadido un signo a $\Delta \mathrm{E}$. Si en una pieza el valor de $\mathrm{L}^{*}$ resultaba mayor que el de la pieza de referencia, el signo se puso positivo y si $\mathrm{L}^{*}$ era menor se puso signo negativo, lo que corresponde, respectivamente, a piezas más claras o más oscuras que la de referencia, según se esquematiza en la tabla I.

\section{RESULTADOS Y DISCUSIÓN.}

\subsection{Caracterización del vidriado y desarrollo de color en el} mismo.

La superficie vidriada de las piezas industriales era de color marrón-anaranjado intenso, con zonas de tonalidad algo más amarillenta, tal como se aprecia en la figura 2.

En la figura 3 se presenta el espectro EDX obtenido al realizar un análisis global de la superficie vidriada. Esta se compone principalmente de silicio y aluminio, cantidades menores de magnesio, potasio, estaño y calcio y pequeñas proporciones de sodio y hierro.

El aspecto de la superficie vidriada en el microscopio electrónico se detalla en la figura 4. Había numerosas partículas brillantes de pequeño tamaño, con una composición muy rica en Sn (probablemente casiterita) y unos cristales de forma dendrítica con análisis muy rico en hierro. Estos cristales eran muy numerosos en las zonas en las que, visualmente, la tonalidad del esmalte era más oscura, por lo que parecían ser los responsables del desarrollo de color.

Para determinar si los cristales de la superficie vidriada formaban parte de la composición del esmalte crudo o si se habían formado durante la cocción, se realizó, en primer lugar una difracción de rayos $\mathrm{X}$ a la mezcla cruda de esmalte. Las fases identificadas fueron : dolomita $\left(\mathrm{CaCO}_{3} \cdot \mathrm{MgCO}_{3}\right)$, cuarzo $\left(\mathrm{SiO}_{2}\right)$, casiterita $\left(\mathrm{SnO}_{2}\right)$ y pequeñas proporciones de illita $\left(6 \mathrm{SiO}_{2} \cdot 3 \mathrm{Al}_{2} \mathrm{O}_{3} \cdot \mathrm{K}_{2} \mathrm{O} \cdot 2 \mathrm{H}_{2} \mathrm{O}\right)$, caolinita $\left(2 \mathrm{SiO}_{2} \cdot \mathrm{Al}_{2} \mathrm{O}_{3} \cdot 2 \mathrm{H}_{2} \mathrm{O}\right)$ y feldespatos sódico y potásico $\left((\mathrm{K}, \mathrm{Na})_{2} \mathrm{O} \cdot 6 \mathrm{SiO}_{2} \cdot \mathrm{Al}_{2} \mathrm{O}_{3}\right.$.).

Posteriormente, se conformó una probeta por colado de la suspensión de esmalte, que, una vez seca, se coció en un horno eléctrico de laboratorio siguiendo un ciclo térmico similar al ciclo (a) de la figura 1, pero manteniendo 8 horas la pieza a $900^{\circ} \mathrm{C}$, una vez se alcanzaba dicha temperatura durante el enfriamiento. La probeta cocida era de color blanco, lo que hacía pensar que el color del vidriado se debiera a la interacción con el soporte, durante la cocción.

La probeta cocida se molturó y se le realizó una DRX. El difractograma obtenido se presenta en la figura 5, en el que se ha incluido también el difractograma del esmalte crudo (línea roja). Al comparar los difractogramas se observa que tras la cocción no hay feldespatos, dolomita ni mineral arcilloso, el

TABLA I.

TONALIDAD DE LAS PIEZAS, RESPECTO A UNA PIEZA DE REFERENCIA.

\begin{tabular}{|lll|}
\hline Pieza clara & $\mathrm{L}^{*}>\mathrm{L}_{\text {ref }}^{*}$ & $\Delta \mathrm{E}>0$ \\
\hline Pieza oscura & $\mathrm{L}^{*}<\mathrm{L}_{\text {ref }}^{*}$ & $\Delta \mathrm{E}<0$ \\
\hline
\end{tabular}

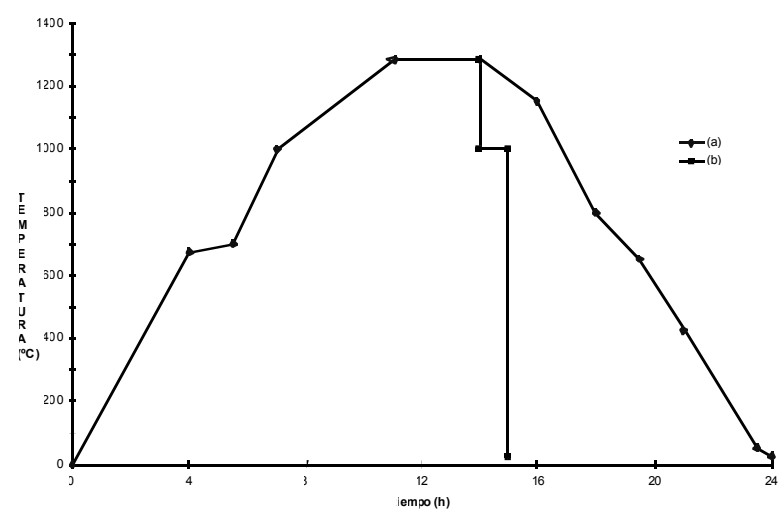

Figura 1. Ciclos térmicos utilizados. (a) Ciclo estándar. (b) Ciclo de enfriamiento rápido.

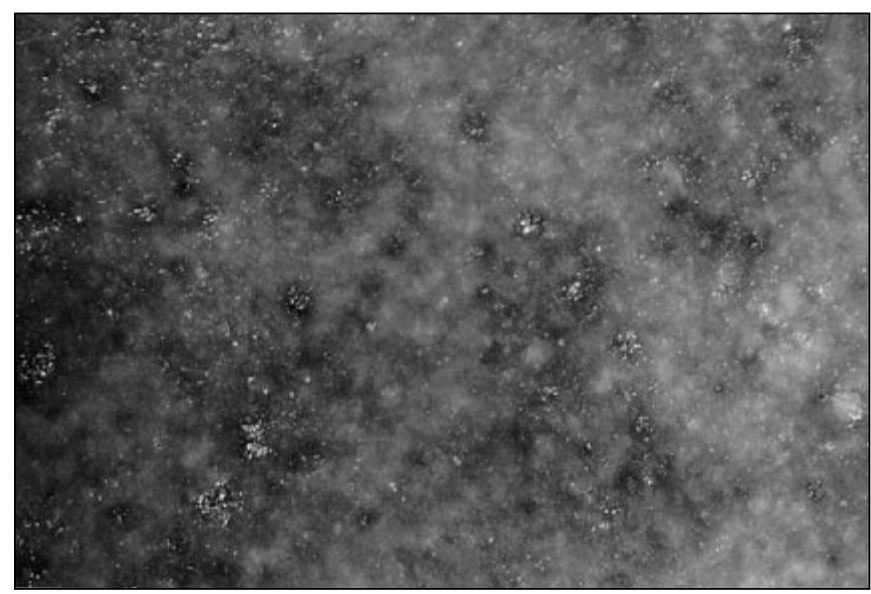

Figura 2. Aspecto de la superficie vidriada de las piezas industriales.

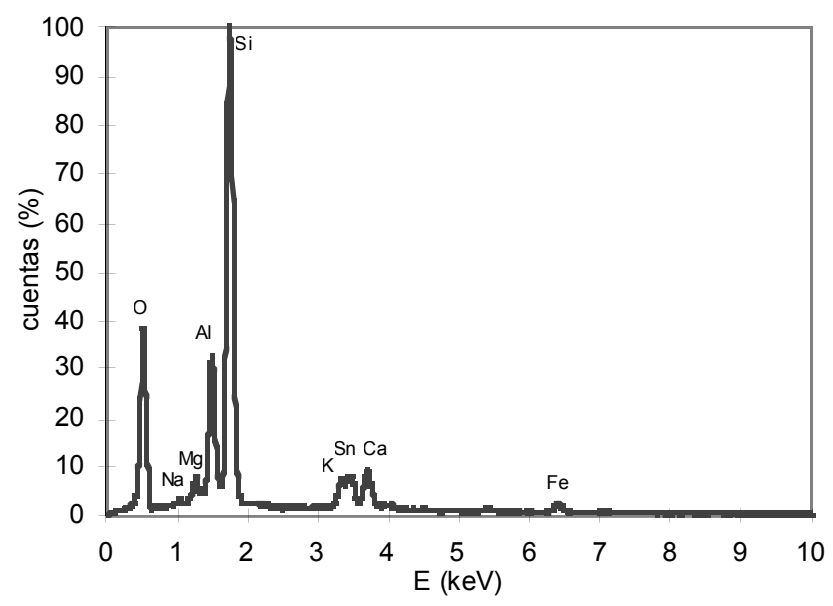

Figura 3.- Microanálisis global en la superficie vidriada de las piezas industriales. 


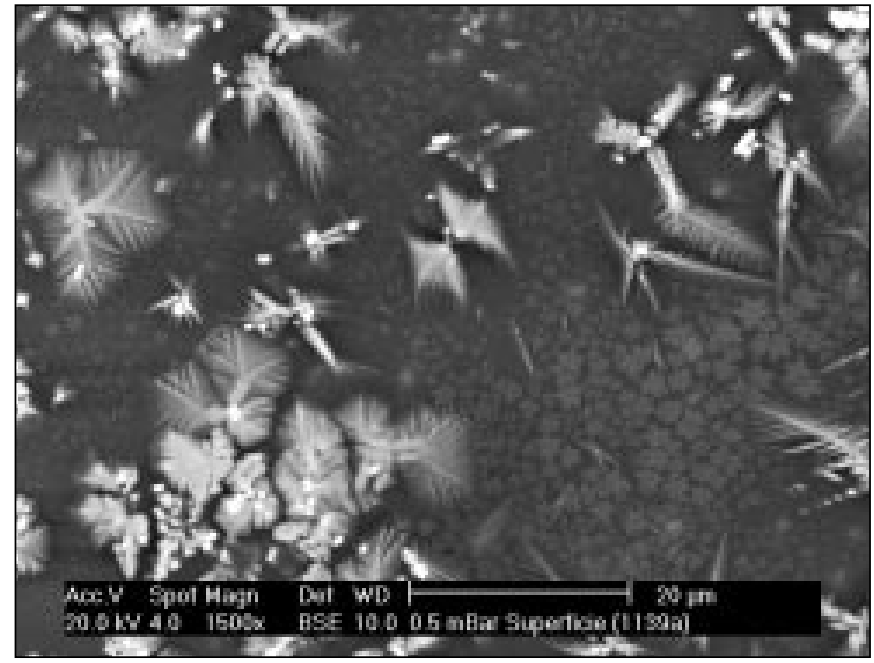

Figura 4. Micrografía de la superficie vidriada de las piezas industriales.

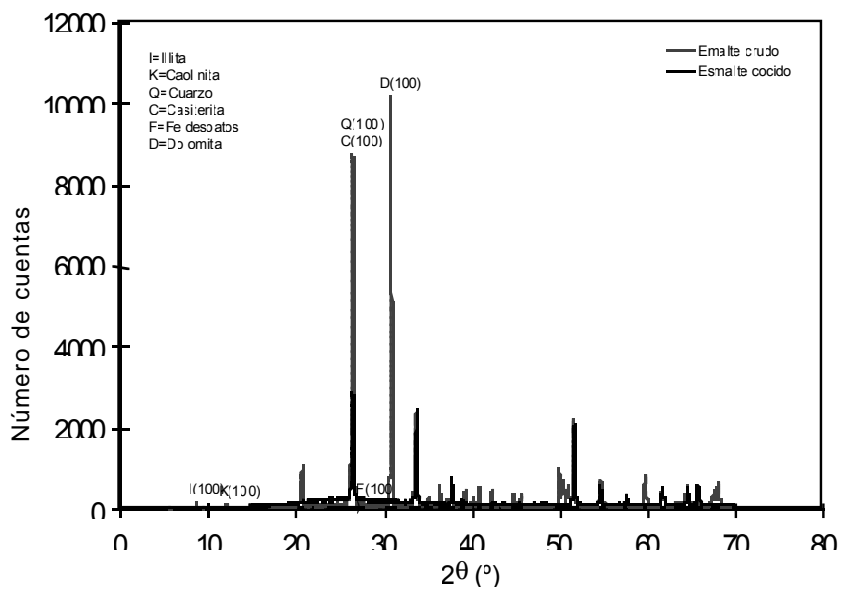

Figura 5.- Difractograma del esmalte crudo(linea roja) y cocido (línea verde).

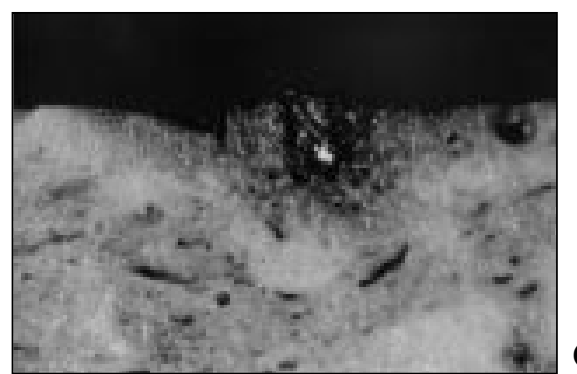

(a)

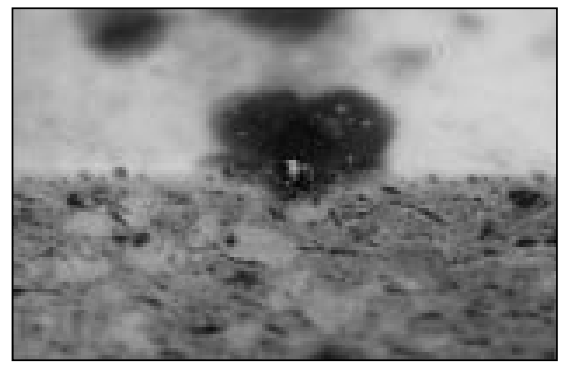

(b)

Figura 6.- (a) Sección de una zona coloreada a 71 aumentos; (b) la misma zona con la probeta inclinada a 26 aumentos cuarzo se ha disuelto y el $\mathrm{SnO}_{2}$ no ha reaccionado, ya que la intensidad de los picos de esta fase es muy parecida en los dos difractogramas.

Para comprobar la hipótesis de la reacción entre el esmalte y el soporte, se aplicó una capa de esmalte sobre el soporte de pavimento y sobre un soporte inerte, de material refractario. Las dos piezas se cocieron simultáneamente según el ciclo térmico (a) de la figura 1. En las piezas cocidas se observó que únicamente la que tenía el soporte de pavimento desarrollaba la coloración rojiza. Se prepararon secciones de las zonas del vidriado en que la coloración era más intensa. El aspecto que presentaban puede observarse en la figura 6. En la superficie del soporte, por debajo de las zonas coloreadas, se observan partículas brillantes de color negro. Estas partículas se encontraban por todo el soporte (figura 7) y estaban compuestas principalmente por hierro (microanálisis de la figura 8).

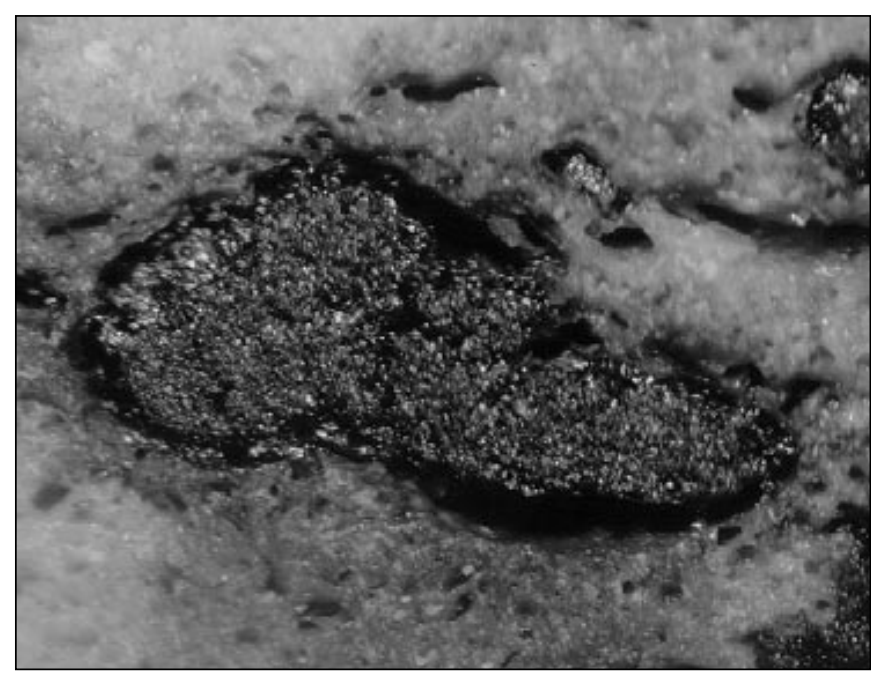

Figura 7.-. Partícula oscura en el interior del soporte.

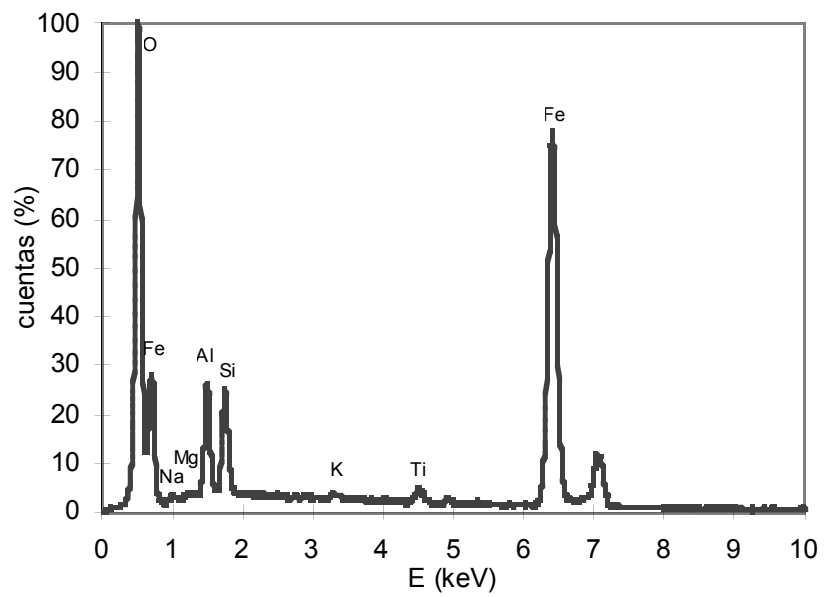

Figura 8.-. Microanálisis de las partículas oscuras del soporte, bajo las zonas coloreadas del vidriado. 
Una vez identificadas las partículas del soporte responsables de la coloración del esmalte, se estudió su reactividad a diferentes temperaturas. Para ello se concentraron mediante separación densimétrica con bromoformo $\left(\mathrm{Br}_{3} \mathrm{CH}, \rho=2.82-2.83\right.$ $\left.\mathrm{g} / \mathrm{cm}^{3}\right)$, aprovechando su elevado contenido en hierro.

La reactividad de las partículas con el esmalte y la difusión de la coloración en el mismo se comprobó cociendo a 1200, 1250 y $1300^{\circ} \mathrm{C}$ de temperatura máxima, probetas cilíndricas de esmalte, obtenidas por colado que, una vez secas, se situaron en un soporte refractario, sobre el que se habían depositado algunas de las partículas separadas del soporte.

La figura 9 muestra las secciones de estas probetas, fotografiadas a los mismos aumentos. Se observa que a medida que aumenta la temperatura de cocción se incrementa la reactividad de estas partículas y en consecuencia el espesor de esmalte coloreado, llegando el color hasta la superficie en la probeta cocida a mayor temperatura (figura 10).

\subsection{Estudio de las variables que afectan al tono}

Industrialmente se había observado que el espesor de capa de engobe y el ciclo térmico con el que se cocían las piezas afectaba a la aparición de tonalidades en el producto final, por lo que en principio estas fueron las variables que se seleccionaron. Una vez determinado que el desarrollo de color se debía a la reacción entre el esmalte y el soporte, se eliminó el espesor de capa de engobe como variable a estudiar, siendo obvio que cuanto mayor fuera ésta menos intenso sería el color del vidriado y se analizó el efecto de la temperatura máxima de cocción, del tiempo de permanencia a dicha temperatura y del contenido en $\mathrm{O}_{2}$ en la atmósfera del horno.

Según la experiencia industrial adquirida con estos materiales, la temperatura máxima de cocción y el tiempo de permanencia de las piezas a dicha temperatura tiene una influencia significativa sobre el color. Para tratar de cuantificar dicha influencia se han cocido, en un horno de laboratorio, piezas esmaltadas industrialmente. El ciclo térmico utilizado ha sido el de la figura 1, modificando la temperatura máxima de cocción, en el intervalo comprendido entre 1255 y $1295^{\circ} \mathrm{C}$. Para cada temperatura máxima de cocción se han ensayado dos ciclos térmicos, con tiempos de permanencia de 3 y 6 horas a dicha temperatura.

En la figura 11 se muestra la influencia de estas variables sobre la coloración de las piezas, pudiéndose observar cómo, conforme aumenta el grado de cocción de las mismas, ya sea por temperatura o por tiempo, las piezas se hacen más oscuras. El efecto de la temperatura es mucho más acusado que el del tiempo. Este efecto combinado temperatura-tiempo puede ser debido a la mayor difusión del hierro a través de la capa de esmalte cuando se alcanzan temperaturas más altas o se incrementa el tiempo de permanencia.

Para analizar la influencia de la atmósfera de cocción sobre el color de las piezas, se cocieron piezas esmaltadas industrialmente, en un horno de atmósfera controlada, con el ciclo térmico de la figura 1. En la figura 12 se ha representado la variación de color de las piezas obtenidas frente al porcentaje de $\mathrm{O}_{2}$ en la atmósfera del horno. Se observa que al disminuir el contenido de oxígeno durante la cocción, las piezas se hacen más oscuras. Esto se debe, probablemente, a una reducción parcial del hierro cuando la atmósfera se empobrece en oxigeno.

Finalmente, se ha estudiado la influencia de la etapa de enfriamiento del ciclo térmico sobre el desarrollo de color en los vidriados. Para ello se han realizado varias cocciones

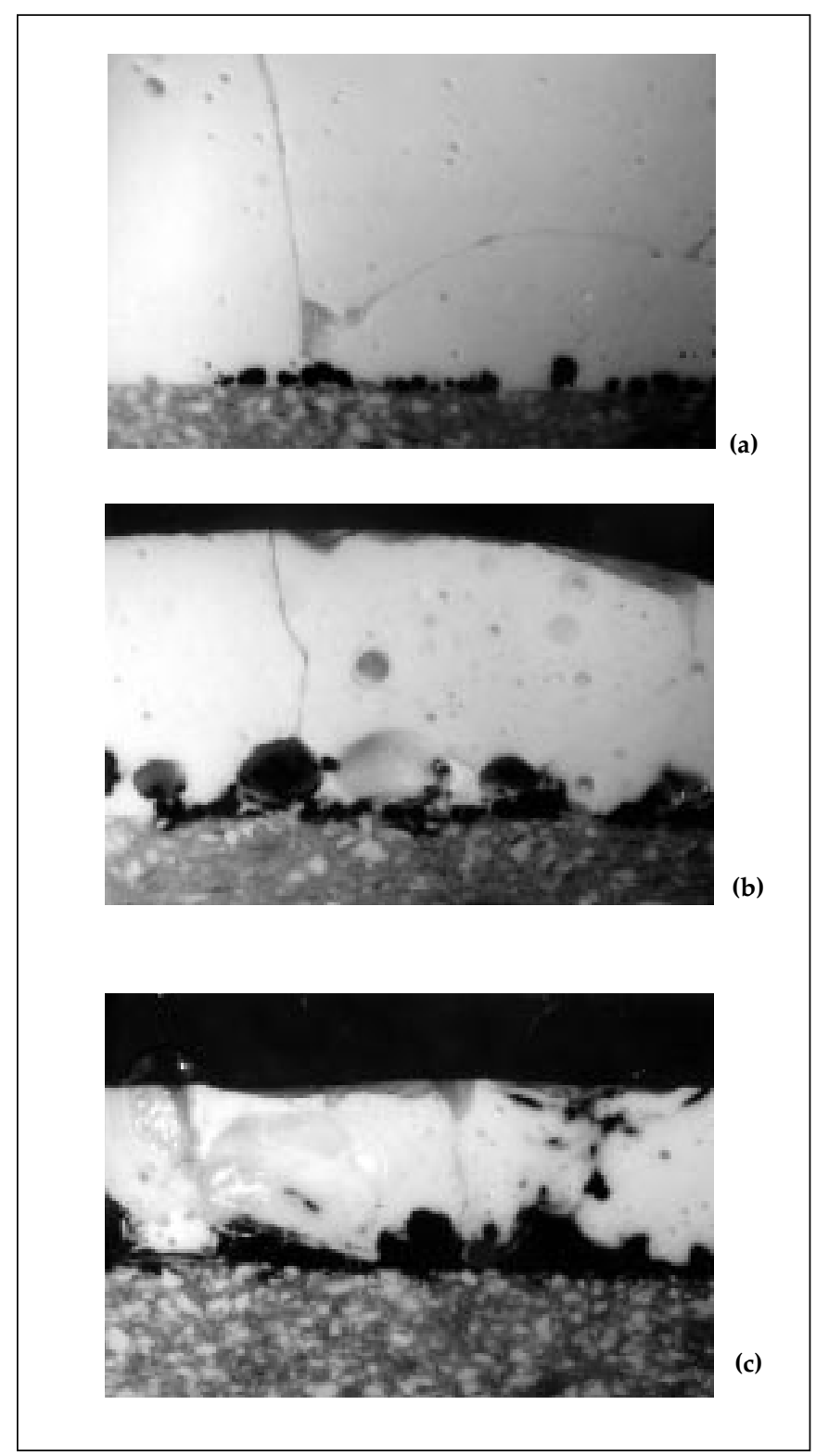

Figura 9.-. Secciones de las probetas de esmalte cocidas sobre pieza de refractario con las partículas oscuras del soporte. Temperatura máxima de cocción : (a) $1200^{\circ} \mathrm{C}$, (b) $1250^{\circ} \mathrm{C}$ y (c) $1300^{\circ} \mathrm{C}$.

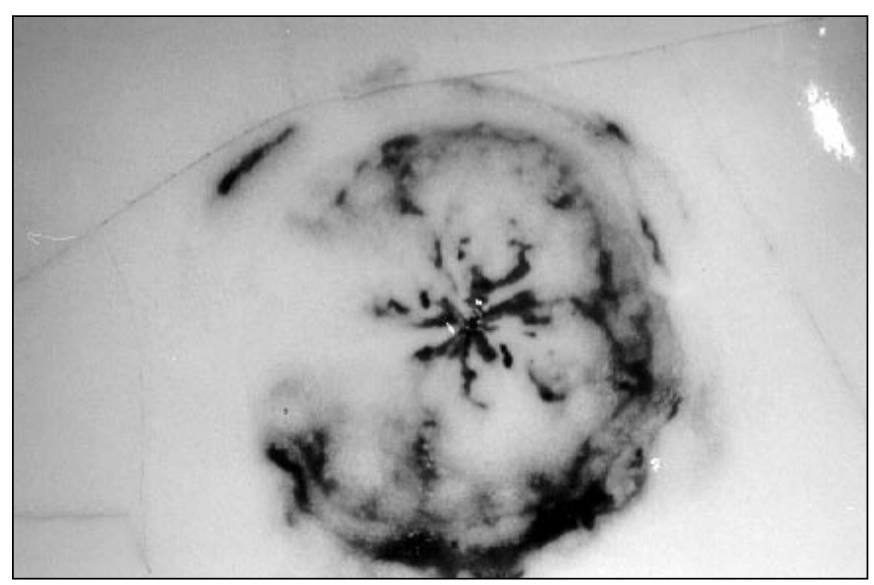

Figura 10.-. Superficie de la probeta cocida a $1300^{\circ} \mathrm{C}$. 


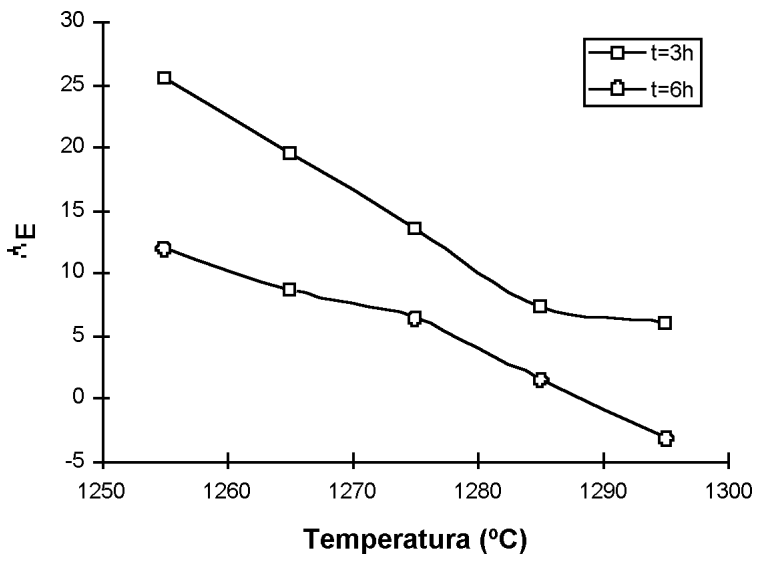

Figura 11.-. Influencia sobre el color, del tiempo y de la temperatura máxima de cocción.

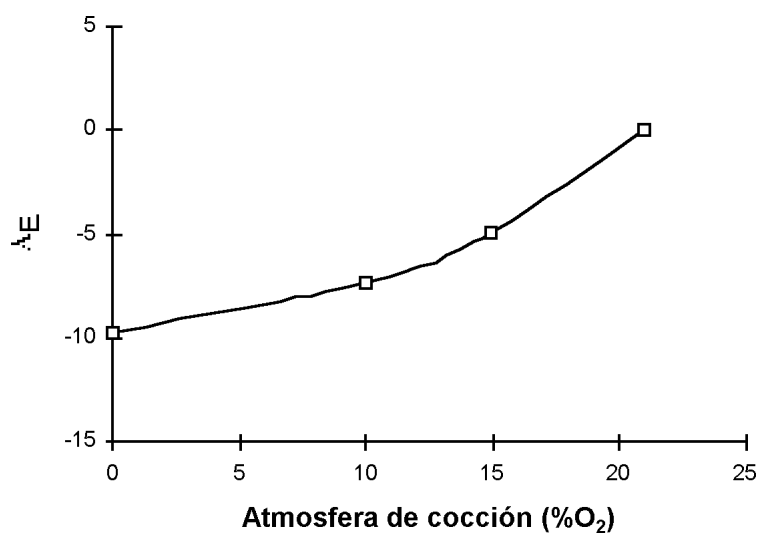

Figura 12.-. Influencia de la atmósfera de cocción sobre el color de las piezas.

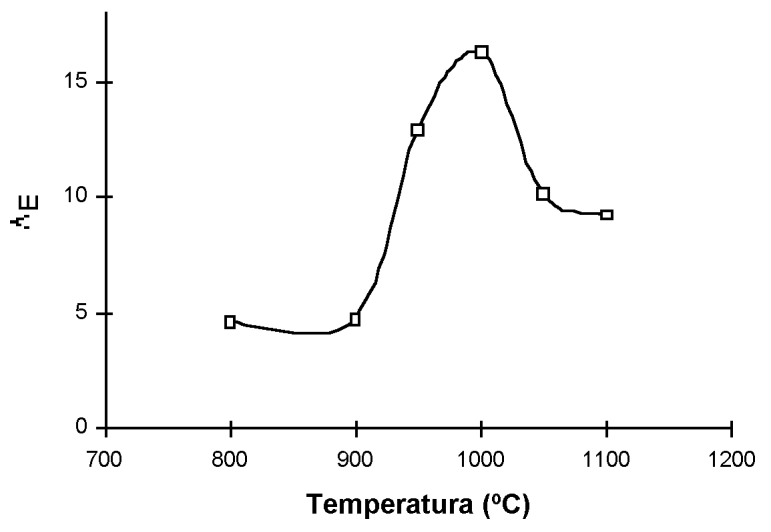

Figura 13. Influencia del ciclo de enfriamiento sobre el color de cocción. siguiendo el ciclo térmico (a) de la figura 1 pero manteniendo la pieza, en el enfriamiento, durante 1 hora a las siguientes temperaturas: $800,900,950,1000,1050$ y $1100^{\circ} \mathrm{C}$. En las piezas obtenidas se han medido las coordenadas cromáticas, obteniendo los resultados que se representan en la figura 13 . Se observa que un aumento del tiempo de permanencia de las piezas, durante el enfriamiento, en el intervalo $1000-900^{\circ} \mathrm{C}$ ocasiona un mayor desarrollo de color en las mismas. Estos resultados indican que la formación de los cristales dendríticos con alto contenido en hierro tiene lugar a velocidad máxima en el citado intervalo de temperaturas.

\section{CONCLUSIONES}

Para estudiar un problema de aparición de tonalidades en piezas de pavimento esmaltado, de tipo rústico, se ha determinado en primer lugar el mecanismo por el que se desarrolla el color en dicho producto. Como esmalte se aplica una mezcla de materias cristalinas que durante la cocción funden, en su mayoría, formando fase líquida. En el soporte se han localizado partículas compuestas fundamentalmente por hierro y aquellas que se encuentran en las inmediaciones de la superficie reaccionan con el vidrio fundido, produciéndose una difusión del hierro a través de la capa de esmalte, que cristaliza durante el enfriamiento dando cristales de forma dendrítica.

Se ha analizado el efecto del ciclo térmico sobre el desarrollo de color en las piezas vidriadas, comprobándose que la intensidad del color aumenta con la temperatura máxima de cocción y con el tiempo de permanencia a dicha temperatura. El aumento de la temperatura supone una disminución de la viscosidad del esmalte fundido y un aumento de la velocidad de difusión del hierro a través del fundido, por lo que se incrementa la reactividad entre el esmalte y las partículas de hierro de la superficie del soporte. Por otra parte, se ha comprobado que al disminuir la velocidad de enfriamiento en el intervalo de temperaturas $1000-900^{\circ} \mathrm{C}$, la coloración de las piezas se hace más intensa. Estos resultados indican que este es el intervalo de temperaturas en el que la cristalización tiene lugar a mayor velocidad.

\section{BIBLIOGRAFÍA}

1. J.E.Houseman, C.J. Koening "Influence of kiln atmospheres in firing structural clay products. Part 2 : color development and burnout" J. Am. Ceram. Soc. 54[2] 82-89 (1971)

2. W. Marko, K. Rohleder "Firing of clinkers in a tunnel kiln with reducing atmosphere" Interbrick 5[2] 11-12 (1989)

3. H. G. Bittner, B. Peterson, G. Walter et al. "Influences of the fast firing process on the red colouring of unglazed stoneware tiles" Tile \& Brick Int. 10[6] 438443 (1994)

4. P. Fisher "Die brenfarbe naturlicher tone (The fired colour of natural clays)" p. 112-122 ZI-Jahrbuch. p 112-122. Bauverlag. Wiesbaden. (1989)

Recibido: 23-9-98

Aceptado: 10-10-98 